\title{
The Construction of the Service System of Innovation and Entrepreneurship Tutors in Colleges and Universities
}

\author{
Yangyong Guo ${ }^{1,2, *}$, Zhongyu $\mathrm{Li}^{1,2}$, Juan $\mathrm{Wei}^{1,2}$ \\ ${ }^{1}$ School of Computer Science, Chengdu Normal University, Chengdu, China \\ ${ }^{2}$ Key Laboratory of interior Layout optimization and Security Institutions of Higher Education of Sichuan Province, \\ Chengdu Normal University, Chengdu, China
}

*Corresponding author. Email: yangyong388@sina.com

\begin{abstract}
Tutor is the key to the innovation and entrepreneurship education in Colleges and universities, and the perfect tutor service system is the guarantee to carry out innovation and entrepreneurship guidance. This paper first expounds the connotation and characteristics of the innovation and entrepreneurship tutor service system in Colleges and universities. On this basis, the paper designs a "three in one progressive cycle" of university innovation and entrepreneurship tutor service system framework of connotation development and qualification, education practice and evaluation, and achievement recognition and incentive, and puts forward the tutor training mechanism of " Pre-work and Post-work and school enterprise combination" to support the above framework, Tutor admittance mechanism, educational practice and evaluation mechanism of "process and achievement integration", multi-directional incentive mechanism and tutor service platform, etc. The service system of the University's entrepreneurship and innovation tutors is an effective way to improve the quality of the University's entrepreneurship and innovation education, which is of great practical significance for the cultivation of the teachers' Entrepreneurship and innovation guidance ability and the improvement of the quality of the entrepreneurship and innovation guidance.
\end{abstract}

Keywords: Innovation and entrepreneurship, Entrepreneurship and innovation education, Tutor service system, Service platform.

\section{高校创新创业导师服务体系建构}

郭阳勇 $1,2, *$ ，李忠玉 ${ }^{1,2}$, 魏娟 1,2

\author{
${ }^{1}$ 成都师范学院计算机科学学院, 成都, 中国 \\ ${ }^{2}$ 成都师范学院室内空间布局优化与安全保障四川省高校重点实验室, 成都, 中国
}

*通讯作者。邮箱: yangyong388@sina.com

中文摘要

导师是高校双创教育的关键，完善的导师服务体系是开展创新创业指导的保障。文章首先阐述了高校创新创业 
导师服务体系的内涵和特点。在此基础上，文章设计了内涵发展与资质、教育实践与评价及成果认定与激励的 “三位一体递进循环” 的高校创新创业导师服务体系构架，并提出了支撑以上架构的 “职前职后+校企结合” 导师培养机制, 导师准入机制, “过程成果融合” 教育实践与评价机制, 多方位激励机制以及导师服务平台等。 高校双创导师服务体系是提升高校双创教育质量的有效路径，对培养教师的双创指导能力、提升双创指导质量 具有重要的现实意义。

关键词：创新创业，双创教育，导师服务体系，服务平台

\section{1. 引言}

近年来, 为鼓励大学生创新创业 (双创), 推动高 校双创教育, 我国政府出台了一列的政策文件, 如国 务院颁布了《关于深化高等学校创新创业教育改革的 实施意见》，明确提出了各高校从 2015 年起全面开 展双创教育改革; 2018 年国务院出台了《关于推动创 新创业高质量发展打造 “双创” 升级版的意见》，提 出强化大学生创新创业教育培训, 在全国高校推广创 业导师制, 把创新创业教育和实践课程纳入高校必修 课体系; 2019 年中共中央、国务院印发了《中国教育 现代化 2035》, 明确提出提升一流人才培养与创新能 力, 以及建设高素质专业化创新型教师队伍, 强化职 前教师培养和职后教师发展的有机衔接。这些政策的 出台为国内的双创教育提供了政策支撑, 双创教育已 经成为高等教育的重要组成部分。

导师制是双创教育领域重要议题 ${ }^{[1]}$, 而围绕导师的 双创服务也是该议题的重要组成之一。关于高校双创 导师的研究, 杨敏 ${ }^{[2]}$ 、刘少宝 ${ }^{[3]}$ 等分别提出在创业教 育中构建校企合作背景下的“双创业导师制”、在创业 课程中构建 “多导师制” 等导师制模式; 刘忠艳 ${ }^{[4]}$ 等 提出通过 “双创” 精细化管理提升师资队伍质量, 构 建双创师资建设路径; 聂晨曦 ${ }^{[5]}$ 、周华等分别构建创 新创业导师能力素质模型、胜任力模型, 提出了提升 导师能力的方法与路径; 吴小春等从创业导师指导效 果影响因素与对策研究, 提出了提升创业导师指导效 果的对策建议。以关键字 “创业导师服务体系” 为主 题在知网检索, 通过分析, 仅有牛彦飞等提出了在职 业教育创业导师服务体系建构路径。结果表明, 现有 的研究成果很少涉及高校创新创业导师服务相关的 研究。本文拟从解析高校双创导师服务体系的内涵和 特点出发, 进而围绕高校培养双创导师内涵发展与资 质认定, 对导师双创教育实践过程与成果评价, 以及 双创教育成果认定与激励三个维度展开分析, 探索构 建高校双创导师服务体系，提升高校双创教育的质量。

\section{2. 创新创业导师服务体系的内涵和特点}

\section{1. 创新创业导师服务}

始于清华大学在 1999 年举行的第一届大学生创 业计划竞赛，自此 “创业导师”一词便衍生出来。创 业导师在指导过程中以教授为目的，向与自己有相似 问题的初始创业者传授专业经验, 帮助创业者开发技 能, 培养创业者的经营管理特质。在创业教育中, 创 新与创业相辅相成, 创新是创业的手段和基础, 而创 业是创新的载体。创新创业导师服务是指在创新创业 活动中, 为创新创业导师的遴选与引入、培训与上岗、 指导与培育、成果与评价等一系列参与双创过程提供 政策措施、平台服务、成果激励等支持。

\section{2. 创新创业导师服务体系内涵}

从本质上来说, 对于高校双创教育, 创新创业导师 服务体系就是为双创导师参与双创指导活动而建立 的全方位支撑体系。具有的来讲, 就是要通过创新创 业导师建设机制, 充分整合学校、企业、行业等双创 师资人才资源, 加强高水平双创导师的培养与引入, 为高校双创教育培育导师及团队; 就是要通过构建双 创教育与指导机制, 规范导师的双创教育与指导流程、 方法及措施, 提升双创指导质量; 就是要通过建立双 创教育过程及成果认定机制, 为导师的双创活动过程 与成果提供科学的评价与认定, 并建立对应的激励机 制, 提高导师的积极性; 就是要通过搭建信息化的导 师服务平台, 为导师的双创活动提供智能化、信息化、 人性化的便捷服务平台，提升双创教育的管理质量与 效率。

\section{3. 创新创业导师服务体系特点}

以开展双创教育, 培养大学生双创人才为前提。教 育的最终目的是唤醒教育对象的生命情感价值, 挖掘 教育对象的创造力, 实现个体自我价值。双创教育是 以培养具有创新精神、创业基本素质和开创型个性的 人才为目标的教育。作为双创教育的重要组成部分, 
高校创业导师服务体系为导师参与双创活动服务, 最 终以培养具有双创意识、双创能力及双创实践的人才 为目标。

以为创业导师服务为中心。高校创新创业导师是 双创活动的实施和指导者, 是双创教育的关键。为创 业导师引进、个体成长及教育指导活动创建良好的支 持, 构建服务体系服务于导师, 有利于规范双创教育, 提升导师的积极性。

以提升双创指导质量与效率为目标。以服务于创 业导师为目的的服务体系的建构, 明确了导师参与创 新创业教育的责权利, 规范了导师指导活动, 有利于 提升双创指导的效率，提高双创教育的质量。

过程与成果兼顾, 成果优先。创新创业导师参与双 创指导的价值体现需要科学的评价, 并配套成果认定 及激励政策, 这样有利于提高导师参与双创活动的积 极性。创新创业导师服务体系构建以过程与成果兼顾、 成果优先的导师评价体系, 即充分认定导师参与双创 活动过程中的培训、指导、研发、建设、管理等工作 量, 同时强化认定资质、效益等成果。对双创过程与 成果取得的成绩，在职称评定、职称定级、奖金分配、 项目申报等方面给予激励与政策倾斜。

\section{3. 创新创业导师服务体系建构}

基于创新创业导师服务体系的特点, 本研究构建 了面向高校、教师、学生及企业的双创导师服务平台, 设计了内涵发展与资质、教育实践与评价以及成果认 定与激励的 “三位一体递进循环” 的高校双创导师服 务体系构架, 并提出了支撑以上架构的 “职前职后+ 校企结合” 导师培养与导师准入机制、导师准入机制, “过程成果融合” 教育实践与评价机制, 多方位激励 机制以及导师服务平台, 如图 1 所示。具体来说, 高 校通过 “职前职后+校企结合” 导师培养机制, 建立以 提升导师内涵发展的双创导师职前职后培养与行业 引入相结合的多级导师资质准入机制, 选拔与培养双 创导师; 对于具有双创教育资质的导师, 通过 “过程 成果融合” 教育实践与评价机制, 对双创教育过程与 成果进行评价; 对于双创成果, 通过成果认定, 构建 多方位激励机制; 通过成果认定与激励, 促进导师双 创教育的积极性, 进而带动高校、企业更多的优秀师 资参与到双创教育中来, 进而促进双创教育的良性发 展。

\section{1. 内涵发展与资质}

内涵发展是指传统教师成为双创导师需要提升自 身内在的双创教育与双创实践能力。双创教育是在传 统教育基础上的实用创新教育, 其在教育方式、能力 培养、教育资源等方面与传统教育有较大差异, 决定 了从事传统教育的教师要开展双创教育必须再学习、 再实践。教师通过参与双创培训、企业实践、科研应 用、双创课程建设等学习途径提升自我, 领会双创教
育的内涵, 掌握双创课程建设与指导、双创项目指导 与实践、项目孵化与应用等双创教育的策略与方法。 资质是指从事双创教育成为双创导师具有的条件、资 格、能力等, 即通过构建双创导师准入机制, 篮选有 条件、有能力、有资格及意愿从事双创教育的教师成 为导师, 就取得了双创导师资质。内涵发展与资质相 辅相成, 只有提升了自身双创教育能力的教师才有可 能取得双创导师资质，反之，取得了双创教育导师资 质的教师已经具有从事双创教育的能力。通过构建双 创具有教师的内涵发展模式与导师准入机制, 为高校 双创导师的培养与引入提供制度保障。

构建 “职前职后+校企结合” 导师培养机制, 探索 导师内涵发展途径。高校为教师从事双创教育自我提 升提供多渠道、多路径支持与保障。通过与企业合作, 建立高校教师双创教育培养的真实项目、训练、课程、 讲座等实践场景，对成为双创导师前的教师进行 “职 前” 培养; 同时结合双创教育实践, 对成为双创导师 后的教师进行 “职后” 培养, 构建双创导师全生命周 期的培养机制。“职前职后+校企结合” 导师培养机制, 通过多种途径实现导师培养。一是通过高校、行业、 企业等不同主题的双创培训, 提升教师双创教育视野, 把握双创教育的现状与发展, 提高双创教育的专业技 能等。二是通过校企合作，教师深入企业一线参与企 业实践, 提升教师的项目研发与管理能力, 锻炼教师 的团队建设与管理能力, 使得教师具有初步的企业营 运与管理能力。三是通过对教师科研及应用的支持, 提升高校科研的应用转化率, 在此过程中, 提升教师 科研实践与应用市场化能力, 提升教师把理论研究转 化成产品应用的能力。四是通过双创课程建设, 打造 专业性或通识性的双创课程, 使得教师具有从事双创 课程讲授与指导的能力。

构建导师准入资质机制, 探索导师选拔路径。导师 准入资质机制涉及高校、企业、行业等主体，需要从 政府层面制定双创导师准入资质宏观政策，在此基础 上, 由各高校因地制宜的构建本校的双创导师准入资 质机制。要从企业、行业等领域引进企业管理经验强、 专业技术精湛的人员加入到导师队伍, 构建双创导师 的重要组成部分; 又要挖掘本校教师的潜力, 多渠道 培养本校教师, 构建双创导师的主要组成部分。

(1) 以双创通识课程、双创专业课程、双创项目、 创客等为服务对象构建高校双创分层多级导师结构 体系。高校双创教育从通识教育到创业实践的不同需 求, 决定了对不同层次的导师的需求。遵循从理论教 学到实践教学渐进式培育原则, 建立侧重理论教学的 通识双创课程、专业双创课程和侧重双创实践的双创 项目、创客教育的四层导师结构, 并对每层划分为初 级、中级、高级, 构建分层多级导师结构体系。

（2）以教师双创培训、企业实践、科研应用、双 创课程建设等取得的成果作为考核对象构建双创导 师准入资质机制。高校通过对教师参与双创培训进行 考核, 认定教师是否具有一定的双创教育思维与方法; 
通过对教师建立的双创课程进行考核, 认定是否具有 从事双创课程相关的教学与指导的能力; 通过对教师 参与企业实践等活动的考核, 认定教师是否具有一定 的双创项目培育与指导的能力; 同时, 对于科研能力 及科研转化突出的教师, 通过对其科研成果应用转化 的评估, 认定其是否具有带动科研师生团队参与产品 应用研发与商业化相关活动的双创教育能力。对于企 业、行业引进的第三方双创导师, 通过对其所在企业 背景、思想品质、个人简历、个人双创教育成绩等进 行考核, 认定其是否具有从事学生团队培育、项目孵 化、创客教育等方法的能力。通过以上考核机制的建 立, 构建了高校双创导师准入资质机制。考核进入高 校双创导师行列的人员, 通过进一步的导师入职培训, 可以进行双创教育相关活动。

\section{2. 教育实践与评价}

教育实践在这里指高校双创教育实践, 指高校双 创导师对学生的双创学习进行有目的、有计划的、有 组织的施加教育影响。双创导师是双创教育实践活动 的主体, 高校学生是双创教育实践活动的对象, 也是 双创教育学习活动的主体。以多导师双创项目培育机 制为基础, 双创导师通过在双创课程、双创团队建设、 双创项目培育及项目孵化实体引导等实践活动对学 生进行指导, 反之, 学生通过双创教育实践指导活动 逐渐构建自身的创新精神与创业意识, 提升自身双创 的理论与实践能力, 熟悉以项目研发、创客等形式开 展创业的方法与路径。评价是指对对双创导师的双创 教育实践活动过程与成果进行判断与分析, 其结果体 现了双创指导活动的个人价值与社会价值。通过构建 导师双创教育实践及评价机制, 对导师在双创课程、 双创团队建设、双创项目培育及项目稃化实体引导等 教育实践活动的教学过程、教学成果等进行评价, 为 双创教育实践提供动力, 为导师的双创教育成果认定 提供基础。

建立导师开展双创教育实践活动路径。双创教育 实践活动涉及双创课程、双创团队建设、双创项目培 育及实体引导等。通过双创课程教育, 为学生构建整 个双创的知识体系以及双创理论基础; 通过对双创团 队建设的指导, 为学生双创活动组建优质团队提供理 论基础与实践案例; 通过对双创项目的指导, 为双创 项目的研发、市场化提供技术、组织及管理支持, 提 升学生的项目研发与项目应用转化能力; 通过市场项 目的实体化引导, 为学生的双创项目按照市场需求规 范化的孵化提供指导与支持, 引导项目团队、创客等 规范化运作。

构建导师双创教育活动“过程成果融合”评价机制。 导师双创教育活动评价机制既要体现双创教育实践 活动的过程, 又要体现双创教育活动的成果, 还应保 障评价的全面性、公平性及科学性。导师参与双创教 育活动的过程与成果是相辅相成, 即双创教育过程性 活动属性反映了导师双创活动的参与程度, 直接决定 双创活动的最后成果; 反之, 双创教育成果的成绩反
映了导师双创教育活动的参与度、积极性以及双创教 育能力。通过对导师在双创课程、双创团队建设、双 创项目培育及项目孵化实体引导等教育实践活动的 教学过程、教学成果等进行评价, 构建导师双创教育 活动 “过程成果融合”评价机制。

（1）以双创教育活动过程性属性如工作量等为考 核评价对象，构建导师双创教育活动过程性评价机制。 导师在双创教育活动过程中, 通过日常的课程建设、 项目指导、团队建设指导等工作，为高校双创教育的 顺利开展做出了贡献。对于日常双创教育活动, 通过 工作量、阶段性工作完成情况等属性的考核, 建立对 导师双创活动的过程性评价制度与方法, 规范双创教 育对导师的过程性管理。

（2）以双创教育活动取得成果证书、经济效益、 社会效益等为考核对象, 构建导师双创教育教学成果 评价机制。双创教育成果具有多样性的特点, 既有显 性的成果, 如成果证书、双创项目数以及经济效益等; 又有短期看不到效益的隐形成果, 如学生的双创精神 与能力的提升、毕业后带动更多的学生自主创业等社 会效益。通过双创成果阶段性跟踪与长期跟踪相结合, 建立双创教育导师成果评价制度与方法, 科学评价导 师双创成果。

\section{3. 成果认定与激励}

成果认定是指在遵循导师双创自我提升过程与资 质以及导师双创教育实践活动评价结果基础上, 对导 师双创活动的过程与成果进行认定, 为建立双创导师 激励机制提供依据。激励是指对导师的双创教育成果 进行奖励, 调动双创导师的积极性, 推动高校导师团 队的良性循环与发展。

（1）建立导师双创成果认定机制。导师的双创成 果认定机制包含对获得导师资质过程与成果的认定, 以及从事双创教育活动过程与成果的认定。通过对过 程与成果两个目标的认定: 一是导师参与双创教育的 过程性认定, 包括工作量、指导项目数量等定量指标; 二是导师参与双创教育的结果成绩认定，包括成果获 奖证书、资质证书、经济效益证明、社会效益证明等 指标，建立全覆盖的双创导师成果认定机制。

（2）建立导师双创多方位激励机制。导师双创激 励机制既是对导师双创教育成果的响应，也是对导师 双创教育价值的体现。双创成果认定包括双创教育过 程以及成果的认定，对双创导师的激励应遵循双创成 果的认定结果, 构建以成果为依据的激励方法与策略。 另一方面，导师双创激励机制应该体现多渠道、全面 性与公平性, 对于校内导师, 与评优评先、职称评定、 职称升级、经济奖励等挂钩, 并在某些领域给予政策 优惠; 对于校外导师, 除了经济奖励、导师评级外, 给与校企合作优先等特殊政策优惠。 


\section{4. 建立导师服务平台}

双创导师服务体系的建立, 为导师开展双创教育 工作提供了规范化的制度与激励政策。但导师服务体 系涉及高校、企业、导师、学生等多用户, 也涉及双 创教育相关业务的多流程, 为了提升双创服务体系的 运行效率, 需建立信息化、智能化的导师服务平台。 通过导师服务平台, 实现双创导师培养成长、双创教 育过程、成果、激励等过程跟踪, 并通过数据分析结 果优化双创导师服务制度, 改善高校双创环境, 提高 双创教育的质量。

\section{4. 结论}

高校双创导师服务体系是以为导师服务为中心， 以提升双创教育质量为目标, 而构建的导师内涵发展 与资质、教育实践与评价以及成果认定与激励的 “三 位一体递进循环” 的高校双创导师服务体系。通过对 导师内涵发展与资质分析, 建立 “职前职后+校企结 合” 导师培养机制, 通过校企合作, 全生命周期培养 双创导师, 并建立良性的导师选拔机制。通过对导师 教育实践与评价以及成果认定的解析, 建立导师双创 教育活动 “过程成果融合” 评价机制, 对导师双创教 育实践活动过程与成果建立科学评价机制。通过成果 认定与激励的分析, 建立以成果认定为依据的多方位 双创成果激励机制。以过程成果相结合的高校双创导 师成果激励机制, 提高了导师双创教育的积极性, 带 动了高校、企业更多的优秀师资参与到双创教育中来, 促进了双创教育导师队伍的良性发展, 进而提升了双 创教育质量。

\section{致谢}

本文得到四川省 2018-2020 年高等教育人才培养 质量和教学改革课题 “产学研驱动模式下大学生创新 创业团队组建与培育研究” (课题编号: JG2018-887)、 成都师范学院教学改革研究课题 “产学研驱动下大学 生创新创业团队培育模式研究与实践” (课题编号: 2019JG2）的资助。

\section{REFERENCES}

[1] SULL IVANR, Entrepreneurial learning and mentoring $[\mathrm{J}]$. International Journal of Entrepreneurial Behavior\&Research,2000,6(3):160-175.

[2] Yang Min, Jia Xinmin. Exploration on the "double entrepreneurship tutorial system" of school enterprise cooperation [J]. Vocational Education Forum, 2011, (31): 78-81.

[3] Liu Shaobao; Tian Qixiang. Exploration on teaching mode reform of multi tutorial "entrepreneurship foundation" course [J]. Heilongjiang Animal Husbandry and veterinary, 2018, (15): 222-225.

[4] Liu Zhongyan. Research on the construction of "mass entrepreneurship and innovation" teachers team from the perspective of fine management $[\mathrm{J}]$. China human resources development, 2016, (5): 8590 .

[5] Nie Chenxi. Research on the ability and quality of innovation and entrepreneurship tutors in Guangdong in the new era [J]. Science and technology management research, 2019, (19): 261266. 